\title{
Correlation between Dentoalveolar Heights and Vertical Skeletal Patterns in Class I Malocclusion in Ethnic Javanese
}

\author{
I. Gusti Aju Wahju Ardani ${ }^{1} \quad$ Ike Sesaria Pratiknjo ${ }^{1} \quad$ Irwadi Djaharu'ddin ${ }^{1}$ \\ ${ }^{1}$ Department of Orthodontic, Faculty of Dental Medicine, \\ Universitas Airlangga, Surabaya, Indonesia \\ Address for correspondence I. Gusti Aju Wahju Ardani, DDS, \\ MSc, PhD, Department of Orthodontic, Faculty of Dental Medicine, \\ Universitas Airlangga, Campus A, JI Prof Dr Moestopo, No. 47, \\ Surabaya 60132, East Java, Indonesia \\ (e-mail: wahju_ardani@fkg.unair.ac.id).
}

Eur J Dent 2021;15:210-215

\section{Abstract \\ Keywords \\ - Class I malocclusion \\ - dentoalveolar height \\ - vertical patterns \\ - Javanese \\ - orthodontic}

Objectives Vertical proportions of the face are important determining factors for diagnosis and planning appropriate orthodontic treatment. Orthodontic patients have different vertical and sagittal skeletal discrepancies, as well as associated varying degrees of dentoalveolar compensations. Dentoalveolar is a functional component of the jaw; it plays a role in occlusal dynamics and forms sagittal and vertical maxilla-mandibula relationships. This study aims to analyze the relationship between dentoalveolar heights and several vertical skeletal patterns in patients with Class I malocclusion in ethnic Javanese.

Materials and Methods The sample consisted of lateral cephalograms of 75 patients (18 samples were male, and 57 were female). Determined by inclusion and exclusion criteria, the participants were selected from an initial sample of 196 patients with skeletal Class I malocclusion (sella-nasion-A and B [ANB] = 1-4 degrees). Cephalometric analysis was performed using OrthoVision2017 digital software. This analysis measured upper anterior dental height (UADH), upper posterior dental height (UPDH), lower anterior dental height (LADH), lower posterior dental height (LPDH), ANB angle, sella-nasion and mandibular plane (SN-MP), sella-nasion and palatal plane (SN-PP), palatal plane and mandibular plane (PP-MP), Frankfort horizontal plane and mandibular plane (FH-MP), sella to gonion (S-Go), articulare to gonion ( $\mathrm{Ar}-\mathrm{Go}$ ), nasion to menton (N-Me), nasion to anterior nasal spine (N-ANS), and anterior nasal spine to menton (ANS-Me). Pearson correlation test was used to assess correlations among all variables $(p<0.05)$.

Results Significant correlations were observed between dentoalveolar heights and SN-MP, S-Go, Ar-Go, N-Me, and ANS-Me $(p<0.05)$.

Conclusions Patients with Class I malocclusion in ethnic Javanese exhibit a significant correlation between dentoalveolar and vertical skeletal patterns. UPDH and/or LPDH have a significantly positive correlation with SN-MP, S-Go, Ar-Go, N-Me, and ANS-Me. The orthodontic correction of the decreased or increased facial height included either the extrusion or intrusion of the anterior or posterior teeth in different ways. published online October 8, 2020
DOI https://doi.org/

10.1055/s-0040-1717156 ISSN 1305-7456.
(C) 2020. European Journal of Dentistry.

This is an open access article published by Thieme under the terms of the Creative Commons Attribution-NonDerivative-NonCommercial-License, permitting copying and reproduction so long as the original work is given appropriate credit. Contents may not be used for commercial purposes, or adapted, remixed, transformed or built upon. (https://creativecommons.org/licenses/by-nc-nd/4.0/) Thieme Medical and Scientific Publishers Pvt. Ltd., A-12, 2nd Floor, Sector 2, Noida-201301 UP, India 


\section{Introduction}

Sagittal and vertical changes occur when the growth period ends in various malocclusions. Skeletal malocclusion is usually associated with dental malocclusion. The sagittal discrepancy is manifested as skeletal Class I, II, or III malocclusion. The vertical discrepancy appears in the form of normodivergent, hypodivergent, or hyperdivergent profile. ${ }^{1}$

A variety of methods had been developed to judge the vertical relation when, in 1946, Tweed introduced the Frankfort-mandibular plane (MP) angle. In the following year, Björk linked the maxillary and mandibular planes to the sella-nasion (SN) plane. In 1948, Riedel measured the MP's inclination toward cranium, and Downs measured the $Y$-axis and the MP angles. ${ }^{2}$ The alveolar bone is a structure that maintains an occlusal relationship based on the changes in the maxilla-mandibular relationships. This mechanism is termed "dentoalveolar compensation" to cover up the skeletal irregularities. ${ }^{3}$

Orthodontic patients have different vertical and sagittal skeletal discrepancies, as well as the associated varying degrees of dentoalveolar compensations. ${ }^{4}$ There are two components of dentoalveolar compensation: (1) the vertical development of basal and dentoalveolar height, and (2) the impact of incisor inclination. ${ }^{5}$

Singh and Sharma found significant correlations between the lower face height and dentoalveolar heights. ${ }^{3}$ The results of their study showed a significant difference between dentoalveolar heights in the long, normal, and short faces and lower anterior facial height (LAFH), except for the lower posterior dentoalveolar height. The upper teeth presented a higher correlation than the lower teeth. ${ }^{3}$ In contrast, Betzenberger et al stated that the upper and lower posterior dentoalveolar heights are decreased in subjects with a high angle (SN-MP) in the permanent tooth period. ${ }^{6}$

The study of the relationship between vertical and dentoalveolar characteristics provides valid results of cephalometric measurements in predicting patient growth and increased quality of treatment and prognosis. ${ }^{7}$ Growth modification from dentoalveolar height can be achieved through orthodontic treatment. This is an important factor in planning orthodontic treatment because, in addition to affecting the maxillofacial system's growth, the face type can also affect the selection of the anchoring system to be used in orthodontic treatment. ${ }^{8,9}$ This study aims to analyze the relationship between dentoalveolar heights and several vertical skeletal patterns in patients with Class I malocclusion among ethnic Javanese.

\section{Materials and Methods}

\section{Sample}

The study was approved by the National Ethics Commission of Health of the Faculty of Dental Medicine Universitas Airlangga (715/HRECC.FODM/X/2019). Malocclusion samples were obtained from the Faculty of Dental Medicine, Universitas Airlangga Dental Hospital, between July 2017 and December 2018. The sample consisted of lateral cephalograms of
75 patients (18 samples were male, and 57 were female). Determined by inclusion and exclusion criteria, the participants were selected from an initial sample of 196 patients with skeletal Class I malocclusion (sella-nasion-A and B [ANB $]=1-4$ degrees). The inclusion criteria required that participants be male or female patients with skeletal Class I, be in the age range of 18 to 35 years, have complete permanent dentition regardless of third molars, and have had no history of previous orthodontic and dental abnormalities (missing teeth, supernumerary, or impacted).

The confidentiality of the patient's identity remains protected and for patients under 17 years of age the informed consent was represented by their parents. All lateral cephalograms were taken with the patients standing in the natural head position. The teeth were held together in centric occlusion, with the lips relaxed when the film was exposed. The cephalometric analysis was then performed using OrthoVision2017 digital software (Ewoosoft Co. Ltd., Gyeonggi-do, South Korea). The reference points, planes, and variables are listed below and shown in -Figs. 1 and 2.

- ANB (degrees): The angle between the points sellanasion-A (SNA) and sella-nasion-B (SNB).

- SN-MP (degrees): The angle between the SN plane and the $\mathrm{MP}$ (GoMe).

- SN-PP (degrees): The angle between the SN and the palatal plane or PP (anterior nasal spine [ANS]-posterior nasal spine [PNS]).

- PP-MP (degrees): The angle between the PP (ANS-PNS) and the MP (gonion-menton [GoMe]).

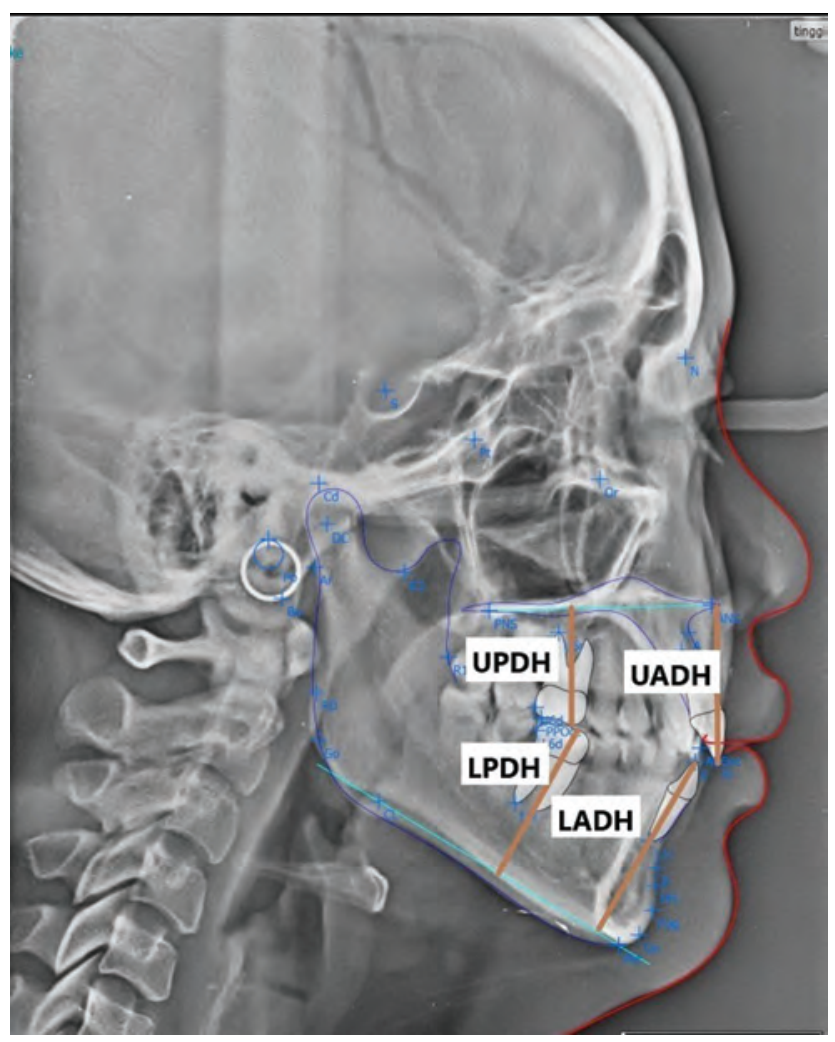

Fig. 1 Dentoalveolar height measurements. LADH, lower anterior dental height; LPDH, lower posterior dental height; UADH, upper anterior dental height; UPDH, upper posterior dental height. 
- FH-MP (degrees): The angle between the Frankfort horizontal (FH) plane (Po-Or) and GoMe.

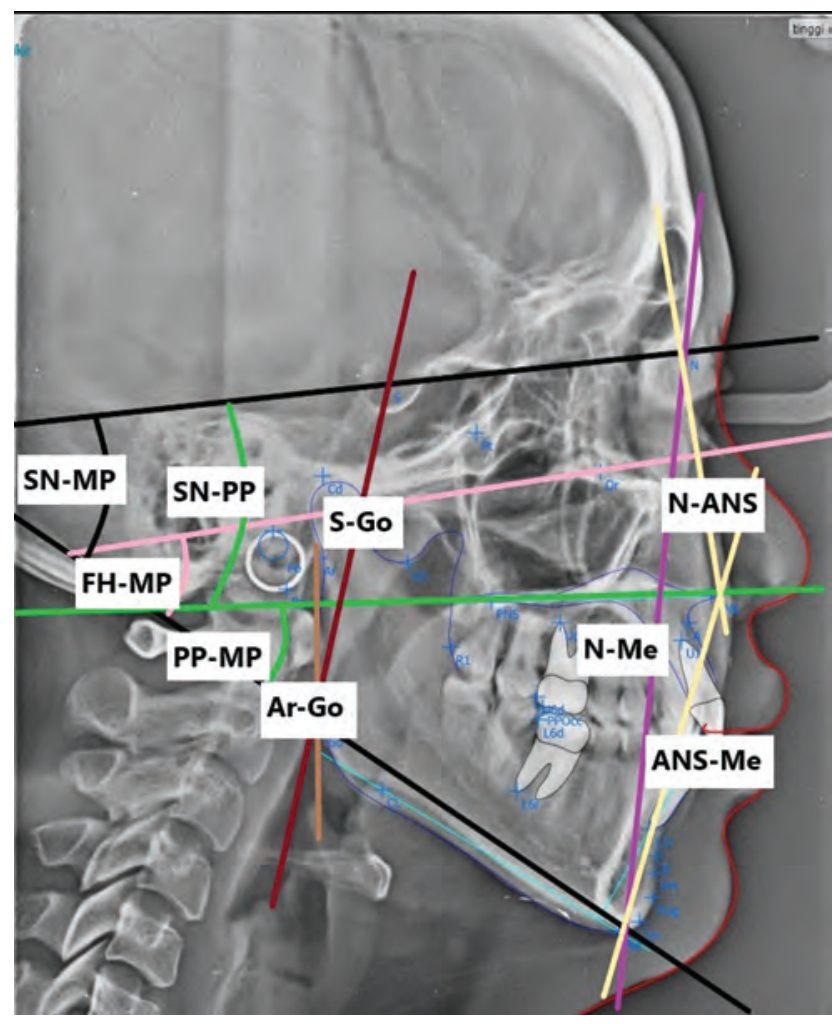

Fig. 2 Vertical pattern measurements. ANS-Me, anterior nasal spine to menton; Ar-Go, articulare to gonion; FH-MP, Frankfort horizontal plane and mandibular plane; N-ANS, nasion to anterior nasal spine; $\mathrm{N}-\mathrm{Me}$, nasion to menton; PP-MP, palatal plane and mandibular plane; $\mathrm{S}-\mathrm{Go}$, sella to gonion; SN-MP, sella-nasion and mandibular plane; $\mathrm{SN}-\mathrm{PP}$, sella-nasion and palatal plane.
- S-Go (mm): A line measured from sella to gonion.

- Ar-Go (mm): A line measured from articulare to gonion.

- $\mathrm{N}-\mathrm{Me}(\mathrm{mm})$ : A line measured from nasion to menton.

- N-ANS (mm): A line measured from nasion to anterior nasal spine (ANS).

- ANS-Me (mm): A line measured from ANS to menton.

- Upper anterior dental height-UADH (mm): The perpendicular length from the incisal edge $U_{1}$ projected to the PP.

- Lower anterior dental height-LADH (mm): The perpendicular length from the incisal edge $L_{1}$ projected to the MP.

- Upper posterior dental height-UPDH ( $\mathrm{mm}$ ): The perpendicular length from the mesiobuccal cusp $U_{6}$ projected to the PP.

- Lower posterior dental height-LPDH (mm): The perpendicular length from the mesiobuccal cusp $L_{6}$ projected to the MP.

\section{Statistical Analysis}

The data were analyzed using descriptive statistics such as mean, standard deviation, and range (minimummaximum) using Statistical Package for Social Sciences 17.0 (SPSS Inc., Chicago, Illinois, United States). The data were checked for normality using the Kolmogorov-Smirnov test and the Shapiro-Wilk test $(p>0.05)$. Pearson correlation test $(p<0.05)$ was used to assess correlations among all variables.

\section{Results}

The normality test results showed normal data distribution $(p>0.05)$. Descriptive statistics are shown planes, and variables are li in - Table $\mathbf{1}$. The study's results suggest some variations of skeletal Class I malocclusion (vertical parameter):

Table 1 Normality test result

\begin{tabular}{|c|c|c|c|c|c|c|}
\hline & \multicolumn{3}{|c|}{ Kolmogorov-Smirnov } & \multicolumn{3}{|c|}{ Shapiro-Wilk } \\
\hline & Statistic & $d f$ & Significance & Statistic & $d f$ & Significance \\
\hline $\mathrm{UADH}$ & 0.085 & 75 & $0.200^{*}$ & 0.986 & 75 & 0.592 \\
\hline UPDH & 0.079 & 75 & $0.200^{*}$ & 0.985 & 75 & 0.546 \\
\hline LADH & 0.062 & 75 & $0.200^{*}$ & 0.986 & 75 & 0.559 \\
\hline LPDH & 0.072 & 75 & $0.200^{*}$ & 0.991 & 75 & 0.872 \\
\hline ANB & 0.113 & 75 & 0.020 & 0.950 & 75 & 0.005 \\
\hline SN-MP & 0.148 & 75 & 0.000 & 0.916 & 75 & 0.000 \\
\hline SN-PP & 0.065 & 75 & $0.200^{*}$ & 0.982 & 75 & 0.386 \\
\hline PP-MP & 0.050 & 75 & $0.200^{*}$ & 0.991 & 75 & 0.875 \\
\hline FH-MP & 0.122 & 75 & 0.008 & 0.953 & 75 & 0.007 \\
\hline S-Go & 0.149 & 75 & 0.000 & 0.935 & 75 & 0.001 \\
\hline Ar-Go & 0.097 & 75 & 0.075 & 0.967 & 75 & 0.049 \\
\hline $\mathrm{N}-\mathrm{Me}$ & 0.120 & 75 & 0.010 & 0.923 & 75 & 0.000 \\
\hline N-ANS & 0.114 & 75 & 0.016 & 0.969 & 75 & 0.060 \\
\hline ANS-Me & 0.092 & 75 & 0.187 & 0.971 & 75 & 0.082 \\
\hline
\end{tabular}

Abbreviations: ANB, sella-nasion-A and B points; ANS-Me, anterior nasal spine to menton; Ar-Go, articulare to gonion; FH-MP, Frankfort horizontal plane and mandibular plane; LADH, lower anterior dental height; LPDH, lower posterior dental height; N-ANS, nasion to anterior nasal spine; N-Me, nasion to menton; PP-MP, palatal plane and mandibular plane; S-Go, sella to gonion; SN-MP, sella-nasion and mandibular plane; SN-PP, sella-nasion and palatal plane; UADH, upper anterior dental height; UPDH, upper posterior dental height.

${ }^{*}$ This is a lower bound of the true significance $(p>0.05)$. 
Table 2 Mean, standard deviation, and normal values of each variable

\begin{tabular}{|l|l|l|l|l|}
\hline \multicolumn{5}{|c|}{ Descriptive statistics } \\
\hline & Minimum & Maximum & Mean & SD \\
\hline UADH & 19.55 & 38.05 & 29.9344 & 3.81054 \\
\hline UPDH & 19.50 & 32.12 & 25.1925 & 2.92729 \\
\hline LADH & 31.87 & 53.04 & 42.7568 & 4.13966 \\
\hline LPDH & 21.94 & 42.50 & 32.5659 & 4.11729 \\
\hline ANB & 0.00 & 3.08 & 2.6229 & 0.95428 \\
\hline SN-MP & 30.8 & 46.07 & 32.3920 & 8.42097 \\
\hline SN-PP & 1.20 & 18.67 & 9.5231 & 4.15188 \\
\hline PP-MP & 10.60 & 37.95 & 25.8525 & 5.50569 \\
\hline FH-MP & 11.44 & 43.06 & 32.3439 & 6.65813 \\
\hline S-Go & 60.11 & 101.36 & 79.8131 & 8.13296 \\
\hline Ar-Go & 29.64 & 67.50 & 47.5641 & 5.92358 \\
\hline N-Me & 111.36 & 156.16 & 125.5063 & 8.72089 \\
\hline N-ANS & 45.29 & 70.99 & 56.7324 & 5.12844 \\
\hline ANS-Me & 51.00 & 94.02 & 71.2189 & 6.59629 \\
\hline
\end{tabular}

Abbreviations: ANB, sella-nasion-A and B points; ANS-Me, anterior nasal spine to menton; Ar-Go, articulare to gonion; FH-MP, Frankfort horizontal plane and mandibular plane; $\mathrm{LADH}$, lower anterior dental height; LPDH, lower posterior dental height; N-ANS, nasion to anterior nasal spine; N-Me, nasion to menton; PP-MP, palatal plane and mandibular plane; SD, standard deviation; S-Go, sella to gonion; SN-MP, sella-nasion and mandibular plane; SN-PP, sella-nasion and palatal plane; UADH, upper anterior dental height; UPDH, upper posterior dental height.

normodivergent (38 patients), hyperdivergent (22 patients), and hypodivergent (15 patients).

A significant correlation was noticed between UPDH/ LPDH and SN-MP. UADH, LADH, UPDH, and LPDH were found to have a significantly positive correlation with $\mathrm{N}-\mathrm{Me}$ and ANS-Me (-Table 2).

A significant correlation was observed between UADH/ LPDH and S-Go. Ar-Go was found to have a significantly positive correlation with LPDH only (- Table 2).

No significant correlation was discerned between UADH, LADH, UPDH, and LPDH and SN-PP, PP-MP, and FH-MP ( - Table 3).

\section{Discussion}

This study focused on the relationship between dentoalveolar heights (UADH, UPDH, LADH, and LPDH) and ANB, SN-MP, SN-PP, PP-MP, FH-MP, S-Go, Ar-Go, N-Me, N-ANS, and ANS-Me. The subjects in this study were Class I skeletal malocclusions with predetermined criteria. In this study, the subjects were required to be over 18 years of age because they have already passed puberty, and the growth phase has stabilized to avoid changes in the vertical dimensions of the jaw arising from the growth process. Components forming the vertical dimensions of the face include the growth of mandible and maxilla and the development of the alveolar process resulting from tooth eruption. Facial growth was affected by several factors, including genetic race, age, gender, nutritional status, and disease. ${ }^{10}$
According to the study's results, the ANB mean value indicated that the patients had skeletal Class I malocclusion. To diagnose sagittal dysplasia appropriately, anteroposterior disharmony was detected. Riedel introduced the ANB angle, which has been used to date to detect sagittal dysplasia.. ${ }^{11}$

A significant correlation was noticed between dentoalveolar height (UADH, UPDH, LADH, and LPDH) and vertical parameters (ANB, SN-MP, SN-PP, PP-MP, FH-MP, S-Go, Ar-Go, N-Me, $\mathrm{p}$, and ANS-Me). Based on Steiner's analysis, the normal ANB value was 0 to $4 \mathrm{~mm}$. This study's mean value was 2.62 degrees ( \pm 0.95 degrees), which means that the maxillary relationship with the mandible was normal, indicating no dysplasia.

In this study, a significant correlation was seen between UPDH/LPDH and SN-MP. This result is supported by Yousif's research, which states that the SN-MP angle has a positive correlation with the height of maxilla or the mandibular molar region among the male subjects, with no positive correlation for female subjects. ${ }^{12}$ In contrast, Betzenberger et al stated that subjects with a high angle (SN-MP) in the permanent tooth period have their upper and lower posterior dentoalveolar heights decreased. ${ }^{6}$ The study's differences could be due to differences in race, sample size, and inclusion and exclusion criteria.

SN-MP describes the relationship between the mandibular arch and the anterior cranial base. A large angle (SN-MP $\geq 37$ degrees) results in vertical face domination, and a small angle (SN-MP $\leq 27$ degrees) results in horizontal face domination. ${ }^{13}$ The inclination of the anterior cranial base (S-N plane) plays an important role in assessing the vertical relation. The cant of the SN plane is affected by the sagittal and vertical movements of the nasion point, which affects the cant of the SN plane. If the nasion's location is higher, it can produce a long face, with the mandible being normal. ${ }^{2}$

This result also indicates that the S-Go line is positively correlated with UADH and LPDH. When the posterior facial height causes the excessive development of the anterior facial height (AFH), then the mandible rotates. ${ }^{14}$ The Ar-Go line is positively correlated with LPDH. This positive correlation is due to an increase in the vertical ramus height, which drives the mandible away from the maxilla and provides more space for the eruption of the posterior teeth.

UADH, UPDH, UADH, and LPDH are positively correlated with N-Me and ANS-Me. This study's results are consistent with those reported in previous studies indicating that molar dentoalveolar height is positively correlated with AFH. Martina et al stated that LAFH has positive effects on the molar region's dentoalveolar height, thereby reinforcing the positive relationship between dentoalveolar and vertical craniofacial dimensions. ${ }^{8}$

Yousif's study also found a positive correlation between LAFH and dentoalveolar height of the molar region in both women and men. ${ }^{12}$ Various studies have proven that AFH and LAFH play a key role in forming the face's vertical disproportion. The anterior facial growth is important because it can reflect the vertical growth rate of the anterior face. ${ }^{15}$

The addition of dentoalveolar vertical height to maxilla will direct mandibular rotation downward and backward. If there is a reduction in dentoalveolar vertical height in the 


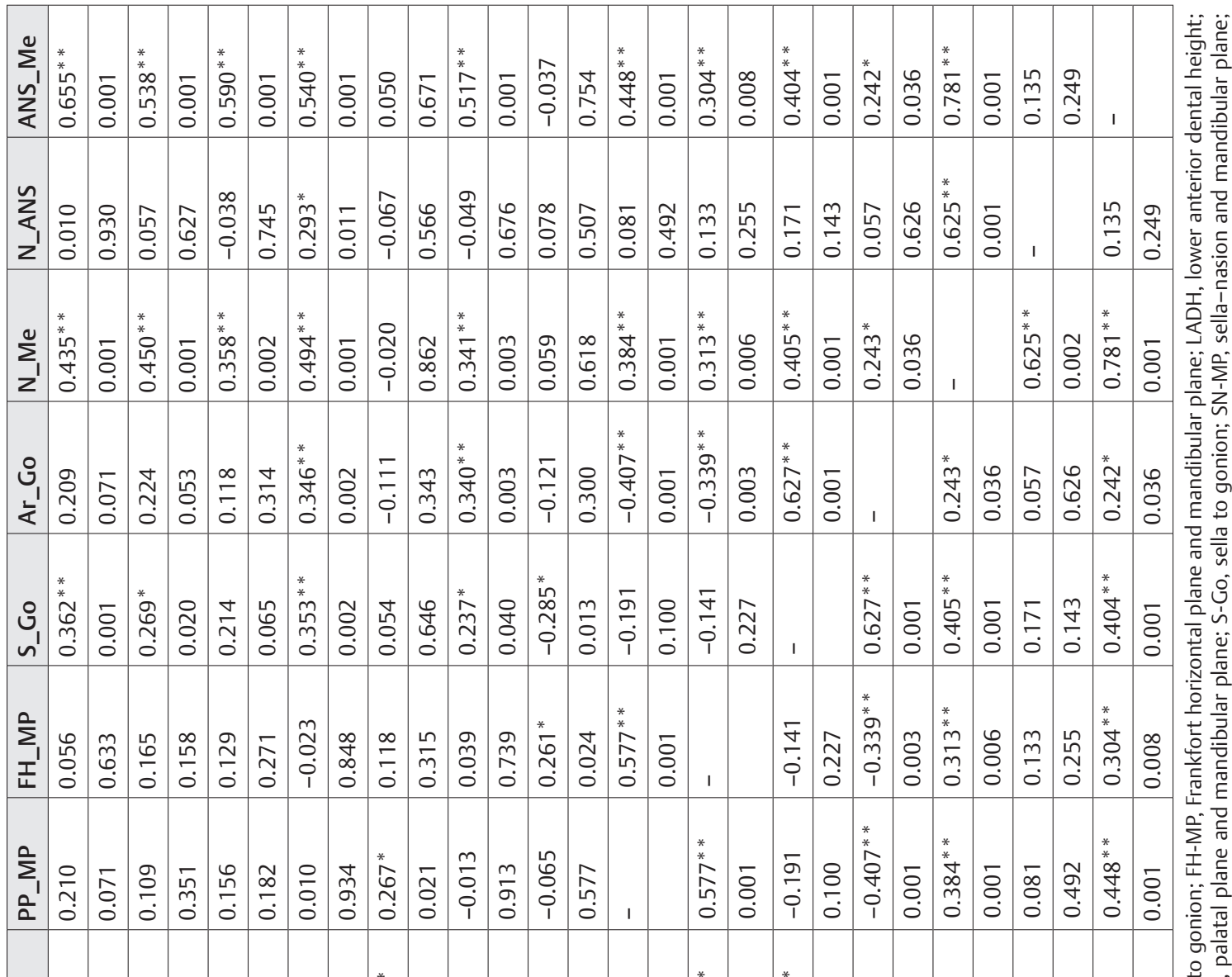

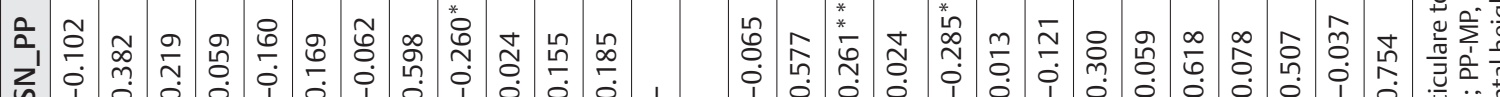

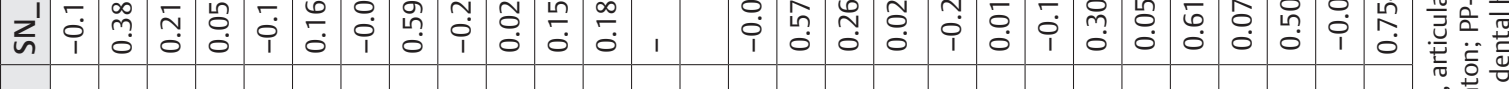

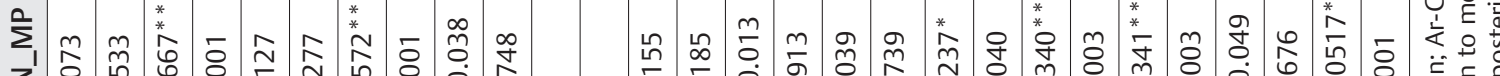

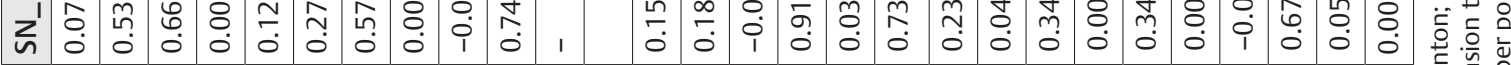

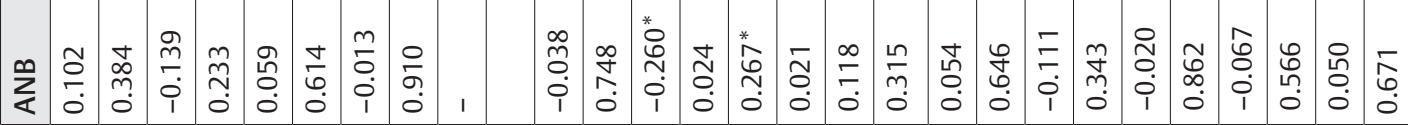

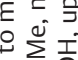

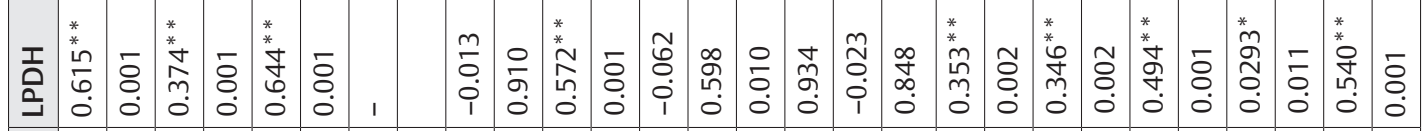

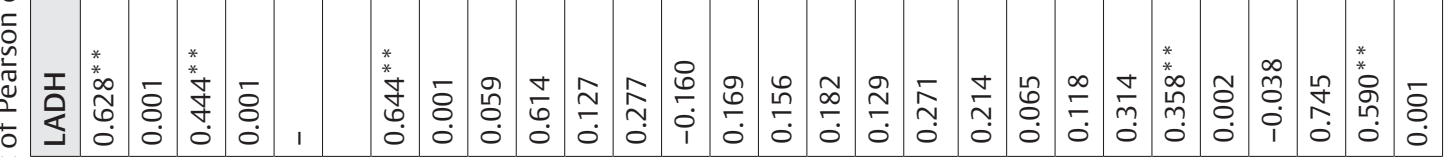

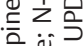

$\frac{n}{0}$

窎高

空. 은

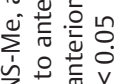

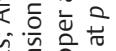

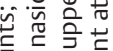

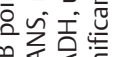

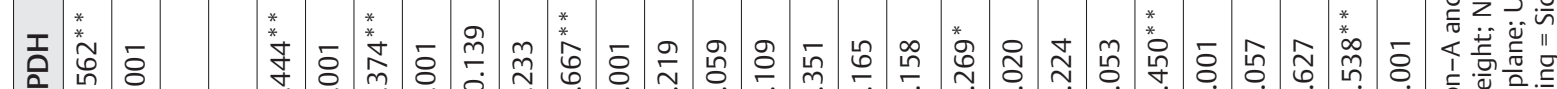

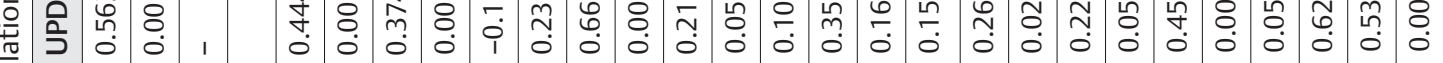


maxilla, it will direct the mandibula rotation upward and forward, which will impact the LAFH. In this study, no correlation was observed between dentoalveolar height and SN-PP, PP-MP, and FH-MP angles. Vertical dysplasia's correlation is crucial in achieving a balanced profile after orthodontic treatment. Many studies have been performed to understand the diagnosis and its implications for dentoalveolar structures. Every effort must be made to treat and correct anterior or posterior dentoalveolar height at fault. ${ }^{16}$

In patients with deep or open bites accompanied by short or long faces, surgical treatment may be considered for dental decompensation or camouflage treatment (dentoalveolar compensation). The selection of treatment for patients should be based on appropriate dentoalveolar compensation and skeletal discrepancy severities. To achieve successful treatment, the dentoalveolar compensation limit must be accurately estimated. ${ }^{5}$

Understanding the relationship between dentoalveolar height and vertical patterns can help orthodontists modify the position of the teeth to correct the skeletal discrepancy in the vertical relation, thus preventing excessive compensations. The orthodontic correction of the decreased or increased facial height includes either the extrusion or intrusion of the anterior or posterior teeth in different ways. In hyperdivergent patients, upper molar intrusion and extrusion of the lower incisors can treat open bites. To treat hypodivergent patients, intrusion and proclination of upper and lower incisors can be performed to avoid deep bites. ${ }^{17}$

The indication for upper incisor intrusion is to promote mandibular anterotation that can avoid overcompensation from LADH.$^{18}$ Many studies have confirmed the value of AFH and LAFH because it can cause vertical facial disproportion. ${ }^{19}$ By correcting the maxillary and mandibular posterior dentoalveolar heights, LAFH can be brought into the normal range, ultimately resulting in improved facial profiles after orthodontic treatment. ${ }^{16}$ Molar extrusion can reduce the facial height to balance backward rotation by promoting the mandible forward rotation with minimal effects on the dimensions of the anterior vertical face. ${ }^{19}$ We recommend further research to evaluate the relationship of these cephalometric parameters with vertical facial growth from various skeletal malocclusions and in other ethnicities.

\section{Conclusions}

Patients with Class I malocclusion in ethnic Javanese exhibit a significant correlation between their dentoalveolar and vertical skeletal patterns. UPDH and/or LPDH showed a significantly positive correlation with SN-MP, S-Go, Ar-Go, $\mathrm{N}-\mathrm{Me}$, and ANS-Me. Understanding the relationship between dentoalveolar height and vertical patterns can help orthodontists modify the position of the teeth to correct the skeletal discrepancy in vertical relation, thus preventing excessive compensations. Orthodontic correction of the decreased or increased facial height includes either extrusion or intrusion of the anterior or posterior teeth in different ways.

\section{References}

1 Moyers RE, Riolo ML, Guire KE, Wainright RL, Bookstein FL. Differential diagnosis of class II malocclusions. Part 1. Facial types associated with class II malocclusions. Am J Orthod 1980;78(5):477-494

2 Nahidh M, Al-chalabi HM, Kadhum AS, et al. The relation among different methods for assessing the vertical jaws relation. Research Gate 2016;15(1):33-38

3 Singh A, Sharma VPTP. A cephalometric evaluation of lower face height and its relationship with dentoalveolar vertical dimensions. J Indian Orthod Soc 2006;39:204-212

4 Islam ZU, Shaikh AJ, Fida M. Dentoalveolar heights in vertical and sagittal facial patterns. J Coll Physicians Surg Pak 2016;26(9):753-757

5 Kuitert R, Beckmann S, van Loenen M, Tuinzing B, Zentner A.Dentoalveolarcompensation in subjects with vertical skeletal dysplasia. AmJ Orthod Dentofacial Orthop 2006;129(5): 649-657

6 Betzenberger D, Ruf S, Pancherz H. The compensatory mechanism in high-angle malocclusions: a comparison of subjects in the mixed and permanent dentition. Angle Orthod 1999;69(1): 27-32

7 Valletta R, Rongo R, Pango Madariaga AC, Baiano R, Spagnuolo G, D’Antò V. Relationship between the condyliongonion-menton angle and dentoalveolar heights. Int J Environ Res Public Health 2020;17(9):E3309

8 Martina R, Farella M, Tagliaferri R. Michelotti A, Quaremba G, van Eijden TMGJ. The relationship between molar dentoalveolar and craniofacial heights. Angle Orthod 2005;75(6): 974-979

9 Tsunori M, Mashita M, Kasai K. Relationship between facial types and tooth and bone characteristics of the mandible obtained by CT scanning. Angle Orthod 1998;68(6):557-562

10 Kjaer I. Mechanism of human tooth eruption: review article including a new theory for future studies on the eruption process. Forum Ortodon 2015;11(3):189-209

11 Ardani IGAW, Wicaksono A, Hamid T. The occlusal plane inclination analysis for determining skeletal class III malocclusion diagnosis. Clin Cosmet Investig Dent 2020;12:163-171

12 Yousif HA. Molar dentoalveolar heights' association with some vertical craniofacial measurements in class I skeletal pattern. J Bagh Coll Dent 2010;22(4):96-101

13 Ardani IGAW, Sanjaya MLSJ, Sjamsudin J. Cephalometric characteristic of skeletal class II malocclusion in Javanese population at Universitas Airlangga Dental Hospital. Contemp Clin Dent 2018;9(September, Suppl 2) :S342-S346

14 Björk A. Prediction of mandibular growth rotation. Am J Orthod 1969;55(6):585-599

15 Ligthelm-Bakker ASWMR, Wattel E, Uljee IH, Prahl-Andersen B. Vertical growth of the anterior face: a new approach. Am J Orthod Dentofacial Orthop 1992;101(6):509-513

16 Hasan A. Change in maxillary and mandibular posterior dentoalveolar heights with variation in lower anterior facial height. Pakistan Oral Dent J 2016;86(3):413-416

17 Chang JZC, Chang WC, Chen KH, et al. How to achieve proper overbite - lessons from natural dentoalveolar compensation. J Dent Sci 2013;8(4):341-347

18 Scheffler NR, Proffit WR, Phillips C. Outcomes and stability in patients with anterior open bite and long anterior face height treated with temporary anchorage devices and a maxillary intrusion splint. Am J Orthod Dentofacial Orthop 2014;146(5):594-602

19 Ardani IGAW, Willyanti I, Narmada IB. Correlation between vertical components and skeletal Class II malocclusion in ethnic Javanese. Clin Cosmet Investig Dent 2018;10:297-302 